\title{
Differentiation of pilocytic and pilomyxoid astrocytomas using dynamic susceptibility contrast perfusion and diffusion weighted imaging
}

Chang Y. Ho ${ }^{1}$, Nucharin Supakul ${ }^{1}$, Parth U. Patel ${ }^{2}$, Vetana Seit ${ }^{1}$, Michael Groswald ${ }^{2}$, Jeremy Cardinal ${ }^{1}$, Chen Lin $^{1}$, Stephen F. Kralik ${ }^{3}$

${ }^{1}$ Indiana University School of Medicine - Department of Radiology and Imaging Sciences

${ }^{2}$ Indiana University School of Medicine - Medical Students

${ }^{3}$ Texas Children's Hospital - Department of Radiology

Corresponding author:

Chang Ho

705 Riley Hospital Drive

MRI department

Indianapolis, IN 46202

cyho@iupui.edu

317-948-8858

A portion of this work was presented at the ASNR 2018 annual meeting in Vancouver, Canada

The authors declare they have no conflicts of interest.

All procedures performed in studies involving human participants were in accordance with the ethical standards of the institutional and/or national research committee (include name of committee + reference number) and with the 1964 Helsinki declaration and its later amendments or comparable ethical standards.

For this retrospective study formal consent is not required.

No funding supported this work.

This is the author's manuscript of the article published in final edited form as:

Ho, C. Y., Supakul, N., Patel, P. U., Seit, V., Groswald, M., Cardinal, J., Lin, C., \& Kralik, S. F. (2020). Differentiation of pilocytic and pilomyxoid astrocytomas using dynamic susceptibility contrast perfusion and diffusion weighted imaging. Neuroradiology, 62(1), 81-88. https://doi.org/10.1007/s00234-019-02310-0 


\section{$\underline{\text { Abstract }}$}

Purpose: Pilocytic (PA) and pilomyxoid astrocytomas (PMA) are related low-grade tumors which occur predominantly in children. PMAs have a predilection for a supratentorial location in younger children with worse outcomes. However, the two have similar imaging characteristics. Quantitative MR sequences such as dynamic susceptibility contrast (DSC) perfusion and diffusion (DWI) were assessed for significant differences between the two tumor types and locations.

Methods: A retrospective search for MRI with DSC and DWI on pathology proven cases of PMA and PA in children was performed. Tumors were manually segmented on anatomic images registered to rCBV, K2, and ADC maps. Tumors were categorized as PA or PMA, with subclassification of supratentorial and infratentorial locations. Mean values were obtained, and tumor groups and locations compared with Student's t-test for significant differences with post-hoc correction for multiple comparisons. ROC analysis for significant t-test values were performed. Histogram evaluation was also performed

Results: A total of 49 patients met inclusion criteria. This included 30 patients with infratentorial PA, 8 with supratentorial PA, 6 with supratentorial PMA, and 5 with infratentorial PMA. Mean analysis showed significantly increased $\mathrm{rCBV}$ for infratentorial PMA $(2.39 \pm 1.1)$ vs PA $(1.39 \pm 0.16, \mathrm{p}=0.0006)$. ROC analysis for infratentorial PA vs PMA yielded $\mathrm{AUC}=0.87(\mathrm{p}<0.001)$. Histogram analysis also demonstrated a higher ADC peak location for PMA $(1.8 \pm 0.2)$ vs PA $(1.56 \pm 0.28)$.

Conclusion: PMA has a significantly higher rCBV than PA in the infratentorial space. DSC perfusion and diffusion MR imaging may be helpful to distinguish between the two tumor types in this location

\section{$\underline{\text { Keywords }}$}

Dynamic susceptibility contrast, perfusion imaging, diffusion weighted imaging, apparent diffusion coefficient, pilocytic astrocytoma, pilomyxoid astrocytoma 


\section{$\underline{\text { Introduction }}$}

Primary brain tumors are the most common childhood solid tumor, representing $29 \%$ of all childhood cancers, and are the most common cause of cancer-related death in the pediatric population. Of these, low grade pilocytic astrocytomas (PA) are the most common [1]. Histologically, PA is characterized by Rosenthal fibers, eosinophilic granular bodies, and alternating cystic regions with densely cellular regions (biphasic architecture). ${ }^{2}$ These tumors have a good prognosis with a 20 year survival rate of $79 \%[2,3]$.

An example of another class of related astrocytoma seen in the pediatric population is the pilomyxoid astrocytoma (PMA). Histologically, these tumors have a more homogenous appearance than PA, characterized by piloid astrocytes in a myxoid background with an absence of Rosenthal fibers or eosinophilic granular bodies. Cells are arranged in an angiocentric pattern and hemorrhage may also be seen [4]. PMA typically affects younger patients, with a mean age at diagnosis of 18 months compared to 58 months for PA [3, 5].

Formerly, PMA were classified as WHO Grade II tumors due to their more aggressive behavior [6, 7]. A study found that PMA histology led to a higher rate of CSF dissemination in patients less than 6 years old [8]. Another study found that the progression free survival at 1 year was 1.8 times higher in patients with PA than patients with PMA [7]. However, in 2016, the WHO reclassified PMA as a grade I tumor as recent studies have shown genetic overlap between PMA and PA, such as carrying the KIAA1549-BRAF fusion gene [9, 10]. More recent studies have shown that the poorer prognosis of PMA may be related to partial resection, chiasmatic location, younger age at presentation, and depth of invasion, in addition to histologic classification [11,12].

Outside of histologic features, it is a challenge to differentiate PA from PMA. Conventional MRI and MR spectroscopy have been unable to differentiate the two classes. The cystic component of PA is hypointense compared to gray matter on T1 images and hyperintense on T2 images. The cyst wall typically enhances with contrast and can demonstrate a strongly enhancing mural nodule. Diffusion weighted imaging shows no restriction of diffusion. Calcification may be seen but surrounding edema is rare.[13] PMA are less likely to have cystic components and lacks large tumor cysts. As a result, PMA tend to appear more homogenous than PA [3]. The myxoid matrix of PMA has been shown to result in increased T2 signal intensity and higher ADC when compared to PA $[14,15]$. Overall, these findings are nonspecific as both categories may show variable contrast enhancement and calcification $[8,16]$. Similarly, both PMA and PA are hypointense on T1 sequences and hyperintense on T2/FLAIR [17]. Additionally, many of these studies suffer from small sample sizes due to the rare nature of PMA. Furthermore, although PA is more commonly found in the posterior fossa ( $60 \%$ in cerebellum), the second most common site is the hypothalamus/optic chiasm, which is the most common location of PMA $(80 \%$ of cases) $[3,13]$. Hemorrhage, which was previously believed to be only seen in $1 \%$ of PA, may be seen in up to $8 \%$ of cases, compared to the $12 \%$ rate of hemorrhage in PMA. MR spectroscopy is also unable to differentiate PMA from PA, with the $\mathrm{Cho} / \mathrm{Cr}$ ratio not being appreciably different, outside of the peritumoral region, where the ratio was increased in PMA due to its aggressive nature [18, 19].

Considering the debate over whether the histologic differences of PA and PMA are a significant factor in clinical outcomes, it is still beneficial to be able to differentiate PA and PMA by imaging preoperatively. Given the difficulty of differentiating PA from PMA on MRI, and the potential for worse outcome in PMA, we assessed whether advanced MRI parameters from dynamic susceptibility contrast (DSC) perfusion and diffusion could distinguish these two tumor types in children.

\section{Materials and Methods}

This study was approved by the Institutional Review Board of Indiana University Purdue University Indianapolis. Given the retrospective nature of the study, no informed consent was needed. A radiology data base search from 2011 to 2016 identified 49 pediatric patients that have a pathology proven diagnosis of PA or PMA with MRI imaging including dynamic susceptibility contrast (DSC) perfusion and DWI prior to surgical resection.

MR Imaging 
DSC perfusion MR images were obtained during the first pass of a bolus of gadobenate dimeglumine (MultiHance, Bracco Diagnostics Inc., Princeton, NJ) on 1.5 and 3T MRI scanners (Siemens Avanto and Verio, Erlangen, Germany) using a gradient echo EPI sequence (TR 1410-2250/TE 30-45 ms, flip angle $90^{\circ}$ ). A contrast medium dose of $0.1 \mathrm{mmol} / \mathrm{kg}$ of body weight was injected followed by a normal saline flush for a total volume of $32 \mathrm{ml}$. When possible, an 18 or 20 -gauge peripheral intravenous access was used with a power injector rate of $5 \mathrm{ml} / \mathrm{s}$. In some cases, primarily with smaller children, only 24 -gauge peripheral intravenous access was possible, limiting contrast injection rate and quality of the contrast bolus. Contrast bolus adequacy was evaluated by two fellowship trained board certified neuroradiologists (C. H. with 13 years' experience and S. K. with 9 years' experience) with certificate of added qualification based on time to signal intensity curves and included or excluded in consensus.

DWI EPI sequences and ADC maps were generated from $b=0$ and $b=1000$. Additional conventional sequences included $\mathrm{T} 1$ weighted images, $\mathrm{T} 2$ weighted images and post contrast $\mathrm{T} 1$ images.

\section{Data Analysis}

Using Olea Sphere 3.0 software (Olea Medical Solutions Inc.; Cambridge, MA), solid tumor volumes (voxel of interest; VOI) were manually traced by neuroradiologists (C.H., N.S. and V.S.) with a second check for accuracy by the senior neuroradiologist (C.H.). Images using T1 post contrast or T2 weighted images were used to trace the entire tumor. Solid enhancing or non-enhancing portions were included, and cystic areas were excluded. DSC is a first pass bolus technique where intravascular contrast decreases $\mathrm{T} 2 *$ signal, allowing measurement of cerebral blood volume. Contrast leakage through the blood brain barrier underestimates CBV. Olea Sphere uses software correction methods using average signal in a time course of normal non-enhancing brain that allows calculation of a corrected CBV and K2, the degree of contrast extravasation [20]. The traced VOI were then registered on K2 leakage, apparent diffusion coefficient (ADC), and corrected relative cerebral blood volume (rCBV) maps generated by the Olea software. Mean values were obtained for each measure for the following subgroups: PA, PMA, supratentorial PA, infratentorial PA, supratentorial PMA, infratentorial PMA, supratentorial tumors (PA and PMA), and infratentorial tumors (PA and PMA). Statistical significance of the differences was determined using student's T-test between all subgroups for K2, rCBV and ADC. Differences were considered statistically significant at $\mathrm{p}<0.05$, after controlling for the false discovery rate $(\alpha=0.05)$ for multiple comparisons [21]. Significant results between PA and PMA subgroups were further analyzed with receiver operating curves and Youden's index for threshold determination (MedCalc Statistical Software version 16.4.3, Medcalc Software bvba, Ostend, Belgium).

All the VOI were exported to a spreadsheet software (Microsoft Excel 2010, Redmond, WA) for histogram analysis for K2, ADC, and rCBV values. Distributions for these parameters were compared between all subgroups. Student's T-tests were performed for the following parameters of the VOI distributions: average, standard deviation, skew, kurtosis, peak location, peak height (normalized), and $5^{\text {th }} / 10^{\text {th }} / 25^{\text {th }} / 50^{\text {th }} / 75^{\text {th }} / 90^{\text {th }} / 95^{\text {th }}$ percentile bins. Differences were considered statistically significant at a $\mathrm{p}<0.05$.

\section{$\underline{\text { Results }}$}

A total of 49 patients met inclusion criteria. The cohort included 30 patients with infratentorial PA, 8 patients with supratentorial PA, 6 patients with supratentorial PMA, and 5 patients with infratentorial PMA. Mean age was 6.7 years (1-15 years, 24 females). Out of all of the 38 PAs only one infratentorial tumor had leptomeningeal metastases at presentation. For the PMAs, only two had leptomeningeal metastases at presentation, both of which were supratentorial tumors. Four PAs (2 supratentorial and 2 infratentorial) required chemotherapy with or without radiation in addition to surgery. Six PMAs (5 supratentorial and 1 infratentorial) required adjuvant therapy after resection. Figure 1 shows an example of patients with PA and PMA, both within the fourth ventricle.

Mean and ROC Analysis 
Comparing mean values for ADC, $\mathrm{K} 2$, and $\mathrm{rCBV}$ values for all subgroups demonstrated significant differences only for rCBV between all PA and PMA (table 1), infratentorial PA vs PMA (table 2) as well as supratentorial vs infratentorial PAs (table 3). After correction for the false discovery rate due to multiple comparisons, only infratentorial PA vs PMA remained significant. ROC analysis for the infratentorial tumors (figure 2) showed AUC $=0.867(\mathrm{p}<0.001)$. Youden's index $(\mathrm{J}=0.7)$ corresponds with a rCBV threshold of $>1.54$ giving $100 \%$ sensitivity (47.8-100) and 70\% specificity (50.6-85.3) for determining PMA from PA.

\section{Histogram Analysis}

The summation histograms of the ADC and rCBV for all PA and PMA tumors are shown in Figure 3. For ADC histogram evaluation, there were statistically significant differences in peak location $(\mathrm{p}=0.005)$, peak height $(\mathrm{p}=0.03)$, and $50^{\text {th }}$ percentile $\mathrm{ADC}$ value $(\mathrm{p}=0.04)$. The peak location for the PA ADC histogram is at a lower value $\left(1.56 \times 10^{-3} \mathrm{~m}\right)$ than the ADC peak location for PMA tumors $\left(1.80 \times 10^{-3} \mathrm{~mm}^{2} / \mathrm{s}\right)$. The peak height for the PA ADC histogram is also lower than the PMA peak height and this is reflected in the broader distribution of the PA ADC values. The median $/ 50^{\text {th }}$ percentile value of the PA ADC distribution $\left(1.59 \times 10^{-3} \mathrm{~mm}^{2} / \mathrm{s}\right)$ is lower than that of the PMA ADC distribution $\left(1.75 \times 10^{-3} \mathrm{~mm}^{2} / \mathrm{s}\right)$. These findings are summarized in Table 4. Similarly, supratentorial PMA also had a higher $(\mathrm{p}=0.03)$ peak location $\left(1.80 \times 10^{-3} \mathrm{~mm}^{2} / \mathrm{s}\right)$ than supratentorial PA $\left(1.45 \times 10^{-3} \mathrm{~mm}^{2} / \mathrm{s}\right)$. Furthermore, rCBV in the infratentorial space was significantly higher for PMA vs PA in the $75^{\text {th }}$ percentile $(\mathrm{p}=0.04)$ and $90^{\text {th }}$ percentile $(\mathrm{p}=0.04)$. These findings are shown in Table 5 . For all PA vs PMA, rCBV in the $5^{\text {th }}$ percentile bin approached significance $(\mathrm{p}=0.05033)$ with PMA demonstrating higher rCBV than PA. Conversely, no significant differences were found between $\mathrm{rCBV}$ for supratentorial versus infratentorial PAs.

Histogram evaluation of all supratentorial tumors versus infratentorial tumors, supratentorial PAs versus infratentorial PAs, supratentorial PMAs versus infratentorial PMAs, and supratentorial PAs versus PMAs were not able to demonstrate significant differences in any metric.

\section{$\underline{\text { Discussion }}$}

Although we did not show significant differences in mean tumor ADC values between PA and PMA, when using histogram analysis, we did find significant increases in ADC for PMA versus PA in the peak location, peak height and $50^{\text {th }}$ percentile bin. This is consistent with the study by Horger et al [14], which found increased T2 and ADC for PMA versus PA likely due to the increased myxoid matrix in PMA. Horger et al [14] is the only other study to date that we are aware of that compared PA and PMA with quantitative MR measures. Previous studies successfully differentiated high versus low grade tumors using ADC, with lower ADC reflecting higher cellularity and grade.

Furthermore, lower ADC can be a predictor of poor outcome in diffuse intrinsic pontine glioma [22]. Although both PA and PMA are considered low grade, due to a monorphous nature of bipolar cells with a higher likelihood of mitotic figures, PMA can be more cellular than PA which should decrease ADC. However, the myxoid matrix in PMAs cause an overall increase in ADC limiting the usefulness of ADC to predict outcome in this tumor.

Ours is the first study to our knowledge to compare PA and PMA using DSC perfusion imaging. Prior DSC MR studies in pediatric brain tumors were able to show a significantly increased $\mathrm{rCBV}$ in high versus low grade tumors [23]. Furthermore, analysis of the time to signal intensity curve from DSC showed a greater T1 based leakage effect as a sensitive and specific sign of both PA and PMA as compared to higher grade tumors such as medulloblastoma [24]. The previous leakage finding explains why we did not see any significant differences in K2, a measure of contrast leakage as both PA and PMA have a high amount of contrast leakage. We were able to find a general increase in rCBV for PMA versus PA, which remained statistically significant after correction for multiple comparisons only for infratentorial tumors. This agrees with the only other known study comparing perfusion between these tumors by Nabavizadeh et al [25], who found significant higher CBF for nine PMAs compared to fifteen PAs on arterial spin labeling. Although CBV and CBF are not identical parameters of perfusion, they are positively correlated in CNS tumors [26]. Increased CBV in particular, is associated with an increase in tumor vascularity [27]. Histologically, a distinguishing feature of PMA are tumor cells in an angiocentric orientation. This angiocentric orientation may contribute to a higher rate of hemorrhage reported with PMA than PA [19]. 
Furthermore, both PMA and PA may have increased vascularity with glomeruloid vascular proliferation [28]. Our study results suggest that an increased $\mathrm{rCBV}$ may be associated with a relative increase in vascularity in PMA compared to PA.

This study was limited by low power due to low numbers of studies in the PMA group. This is due to the rarity of PMA. The disparity in the size of the PA and PMA groups reduced the robustness of the statistical analysis. Furthermore, supratentorial PA are much less common than infratentorial PA, diminishing the power of that comparison [13]. Increased power might elicit significant differences that were not present in the current analysis, potentially allowing differentiation of PMA from PA in the supratentorial compartment. Quantitative perfusion or diffusion data may also be helpful to predict BRAF mutation, which were not available for most of the tumors in our cohort.

\section{Conclusion}

Dynamic susceptibility contrast perfusion demonstrates a higher relative cerebral blood volume for pilomyxoid astrocytoma compared to pilocytic astrocytoma, particularly in the infratentorial space. This may provide a useful understanding of the radiology pathology correlation of these related neoplasms and provide a basis for imaging differentiation.

Conflict of interest statement:

We declare that we have no conflict of interest 
1. Ostrom QT, de Blank PM, Kruchko C, Petersen CM, Liao P, Finlay JL, et al. (2015) Alex's Lemonade Stand Foundation Infant and Childhood Primary Brain and Central Nervous System Tumors Diagnosed in the United States in 2007-2011. Neuro Oncol 16 Suppl 10:x1-x36. 10.1093/neuonc/nou327

2. Burkhard C, Di Patre PL, Schuler D, Schuler G, Yasargil MG, Yonekawa Y, et al. (2003) A populationbased study of the incidence and survival rates in patients with pilocytic astrocytoma. J Neurosurg 98:1170-1174. 10.3171/jns.2003.98.6.1170

3. Komotar RJ, Mocco J, Carson BS, Sughrue ME, Zacharia BE, Sisti AC, et al. (2004) Pilomyxoid astrocytoma: a review. MedGenMed 6:42.

4. Kleinschmidt-DeMasters BK, Donson AM, Vogel H, Foreman NK (2015) Pilomyxoid Astrocytoma (PMA) Shows Significant Differences in Gene Expression vs. Pilocytic Astrocytoma (PA) and Variable Tendency Toward Maturation to PA. Brain Pathol 25:429-440. 10.1111/bpa.12239

5. Ceppa EP, Bouffet E, Griebel R, Robinson C, Tihan T (2007) The pilomyxoid astrocytoma and its relationship to pilocytic astrocytoma: report of a case and a critical review of the entity. J Neurooncol 81:191-196. 10.1007/s11060-006-9216-z

6. Burger PC (2000) Pilocytic astrocytoma. Pathology and Genetics of Tumours of the Nervous System

7. Tihan T, Fisher PG, Kepner JL, Godfraind C, McComb RD, Goldthwaite PT, et al. (1999) Pediatric astrocytomas with monomorphous pilomyxoid features and a less favorable outcome. J Neuropathol Exp Neurol 58:1061-1068.

8. Alkonyi B, Nowak J, Gnekow AK, Pietsch T, Warmuth-Metz M (2015) Differential imaging characteristics and dissemination potential of pilomyxoid astrocytomas versus pilocytic astrocytomas. Neuroradiology 57:625-638. 10.1007/s00234-015-1498-4

9. Louis DN, Perry A, Reifenberger G, von Deimling A, Figarella-Branger D, Cavenee WK, et al. (2016) The 2016 World Health Organization Classification of Tumors of the Central Nervous System: a summary. Acta Neuropathol 131:803-820. 10.1007/s00401-016-1545-1

10. Collins VP, Jones DT, Giannini C (2015) Pilocytic astrocytoma: pathology, molecular mechanisms and markers. Acta Neuropathol 129:775-788. 10.1007/s00401-015-1410-7

11. Fernandez C, Figarella-Branger D, Girard N, Bouvier-Labit C, Gouvernet J, Paz Paredes A, et al. (2003) Pilocytic astrocytomas in children: prognostic factors--a retrospective study of 80 cases. Neurosurgery 53:544-553; discussion 554-545.

12. Cin H, Meyer C, Herr R, Janzarik WG, Lambert S, Jones DT, et al. (2011) Oncogenic FAM131B-BRAF fusion resulting from $7 \mathrm{q} 34$ deletion comprises an alternative mechanism of MAPK pathway activation in pilocytic astrocytoma. Acta Neuropathol 121:763-774. 10.1007/s00401-011-0817-z

13. Plaza MJ, Borja MJ, Altman N, Saigal G (2013) Conventional and advanced MRI features of pediatric intracranial tumors: posterior fossa and suprasellar tumors. AJR Am J Roentgenol 200:1115-1124.

10.2214/AJR.12.9725

14. Horger M, Vogel MN, Beschorner R, Ernemann U, Worner J, Fenchel M, et al. (2012) T2 and DWI in pilocytic and pilomyxoid astrocytoma with pathologic correlation. Can J Neurol Sci 39:491-498.

15. Komotar RJ, Zacharia BE, Sughrue ME, Mocco J, Carson BS, Tihan T, et al. (2008) Magnetic resonance imaging characteristics of pilomyxoid astrocytoma. Neurol Res 30:945-951. 10.1179/174313208X322806

16. White JB, Piepgras DG, Scheithauer BW, Parisi JE (2008) Rate of spontaneous hemorrhage in histologically proven cases of pilocytic astrocytoma. J Neurosurg 108:223-226. 10.3171/JNS/2008/108/2/0223 
17. Arslanoglu A, Cirak B, Horska A, Okoh J, Tihan T, Aronson L, et al. (2003) MR imaging characteristics of pilomyxoid astrocytomas. AJNR Am J Neuroradiol 24:1906-1908.

18. Morales H, Kwock L, Castillo M (2007) Magnetic resonance imaging and spectroscopy of pilomyxoid astrocytomas: case reports and comparison with pilocytic astrocytomas. J Comput Assist Tomogr 31:682-687. 10.1097/RCT.0b013e31803219b0

19. Linscott LL, Osborn AG, Blaser S, Castillo M, Hewlett RH, Wieselthaler N, et al. (2008) Pilomyxoid astrocytoma: expanding the imaging spectrum. AJNR Am J Neuroradiol 29:1861-1866. 10.3174/ajnr.A1233

20. Skinner JT, Moots PL, Ayers GD, Quarles CC. On the Use of DSC-MRI for Measuring Vascular Permeability. AJNR Am J Neuroradiol 37(1):80-7

21. Benjamini Y and Hochberg Y (1995) Controlling the false discovery rate: a practical and powerful approach to multiple testing. J R Stat Soc Series B Stat Methodol 57 (1): 289-300.

22. Poussaint TY, Vajapeyam S, Ricci KI et al. Apparent diffusion coefficient histogram metrics correlate with survival in diffuse intrinsic pontine glioma: a report from the Pediatric Brain Tumor Consortium. Neuro Oncol. 2016 May;18(5):725-34

23. Ho CY, Cardinal JS, Kamer AP, Kralik SF. (2015) Relative cerebral blood volume from dynamic susceptibility contrast perfusion in the grading of pediatric primary brain tumors. Neuroradiology 57(3):299-306.

24. Ho CY, Cardinal JS, Kamer AP, et al. (2016) Contrast Leakage Patterns from Dynamic Susceptibility Contrast Perfusion MRI in the Grading of Primary Pediatric Brain Tumors. AJNR Am J Neuroradiol 37(3):544-51

25. Nabavizadeh SA, Assadsangabi R, Hajmomenian M, et al. (2015) High accuracy of arterial spin labeling perfusion imaging in differentiation of pilomyxoid from pilocytic astrocytoma. Neuroradiology 57:527-533.

26. Järnum H, Steffensen EG, Knutsson L et al. (2010) Perfusion MRI of brain tumours: a comparative study of pseudo-continuous arterial spin labelling and dynamic susceptibility contrast imaging. Neuroradiology 52(4):30717

27. Aronen HJ, Gazit IE, Louis DN et al. (1994) Cerebral blood volume maps of gliomas: comparison with tumor grade and histologic findings. Radiology 191(1):41-51

28. Matyja E, Grajkowska W, Stępień K, Naganska E. (2016) Heterogeneity of histopathological presentation of pilocytic astrocytoma - diagnostic pitfalls. A review. Folia Neuropathol. 54(3):197-211. 


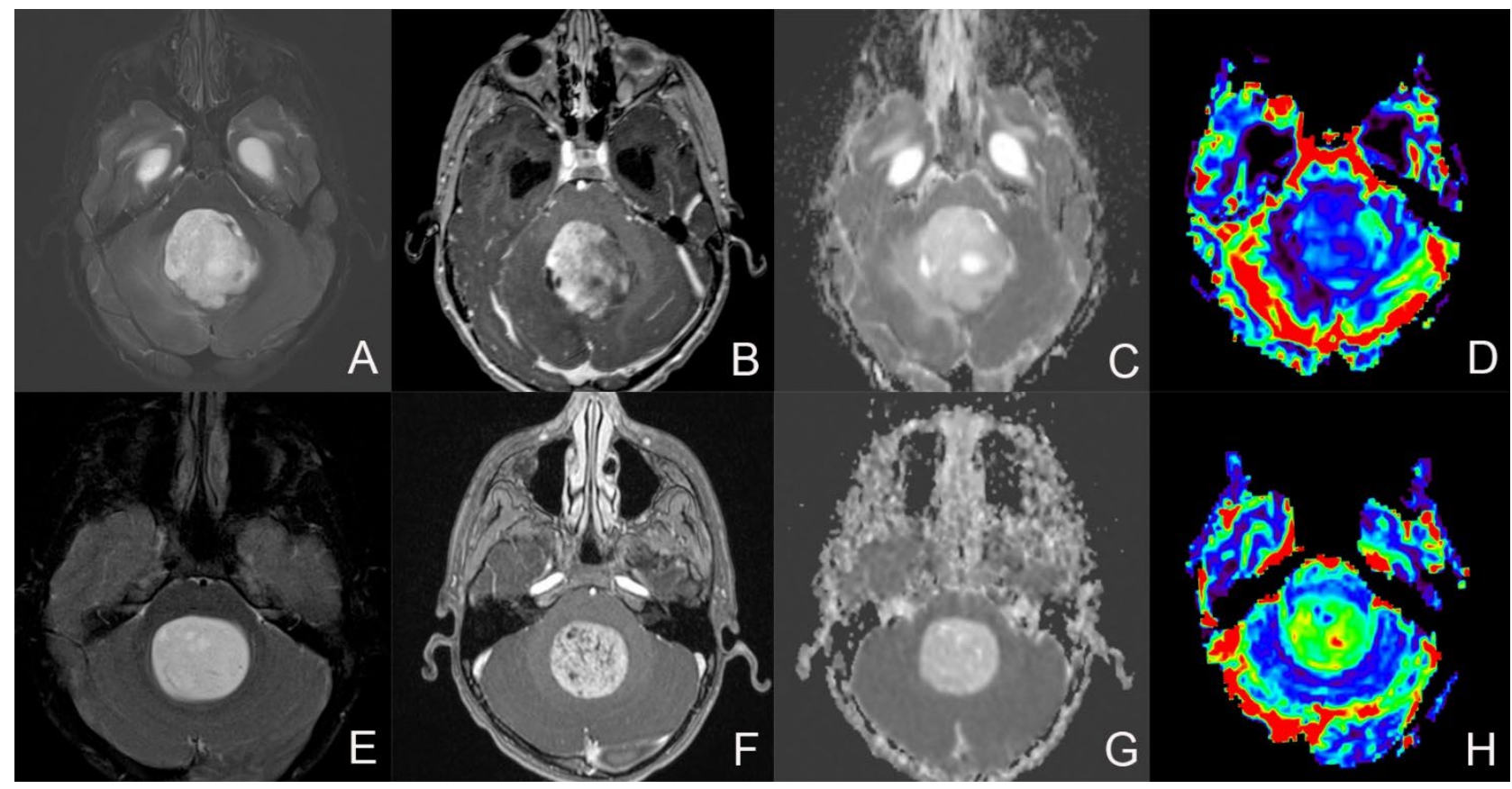

Figure 1. 5 yo female with pilocytic astrocytoma (A-D) compared with a 7 yo male with pilomyxoid astrocytoma $(\mathrm{E}-\mathrm{H})$ both within the fourth ventricle. There is no appreciable difference in T2 hyperintensity ( $A$ and $E$ ), heterogeneous enhancement ( $B$ and $F$ ), and increased $A D C$ ( $C$ and $G$ ). Color rCBV maps show a qualitative increased perfusion for pilomyxoid astrocytoma $(H)$ vs pilocytic astrocytoma $(D)$. 


\begin{tabular}{|c|c|c|c|c|c|c|}
\hline & \multicolumn{2}{|l|}{ PA } & \multicolumn{4}{|l|}{ PMA } \\
\hline & Mean & $95 \% \mathrm{Cl}$ & Mean & $95 \% \mathrm{Cl}$ & P Value & Corrected \\
\hline $\begin{array}{l}\mathrm{ADC}\left(\mathrm{x} 10^{-3}\right. \\
\left.\mathrm{mm}^{2} / \mathrm{s}\right)\end{array}$ & 1.64 & \pm 0.09 & 1.75 & \pm 0.16 & 0.24 & 0.24 \\
\hline $\mathrm{K} 2\left(\mathrm{~min}^{-1}\right)$ & 463.2 & \pm 112.4 & 671.4 & \pm 353.5 & 0.12 & 0.18 \\
\hline rCBV & 1.49 & \pm 0.18 & 1.98 & \pm 0.52 & 0.02 & 0.06 \\
\hline
\end{tabular}

Table 1. Comparison of the mean ADC, K2, rCBV for all PAs versus PMAs. Significant values are bolded.

\begin{tabular}{|c|c|c|c|c|c|c|}
\hline & \multicolumn{2}{|c|}{$\begin{array}{l}\text { INFRATENTORIAL } \\
\text { (PA) }\end{array}$} & \multicolumn{2}{|c|}{$\begin{array}{l}\text { INFRATENTORIAL } \\
\text { (PMA) }\end{array}$} & \multirow[b]{2}{*}{ P Value } & \multirow[b]{2}{*}{ Corrected } \\
\hline & Mean & $95 \% \mathrm{Cl}$ & Mean & $95 \% \mathrm{Cl}$ & & \\
\hline $\begin{array}{l}\mathrm{ADC}\left(\times 10^{-3}\right. \\
\left.\mathrm{mm}^{2} / \mathrm{s}\right)\end{array}$ & 1.68 & \pm 0.1 & 1.81 & \pm 0.36 & 0.32 & 0.32 \\
\hline $\mathrm{K} 2\left(\mathrm{~min}^{-1}\right)$ & 465.2 & \pm 130.2 & 803.1 & \pm 906.9 & 0.1 & 0.15 \\
\hline rCBV & 1.39 & \pm 0.16 & 2.39 & \pm 1.1 & 0.0002 & 0.0006 \\
\hline
\end{tabular}

Table 2. Comparison of the mean ADC, K2, rCBV for infratentorial tumors. Significant values are bolded.

\begin{tabular}{|c|c|c|c|c|c|c|}
\hline \multirow[b]{3}{*}{$\begin{array}{l}\mathrm{ADC}\left(\times 10^{-3}\right. \\
\left.\mathrm{mm}^{2} / \mathrm{s}\right)\end{array}$} & \multicolumn{2}{|c|}{$\begin{array}{l}\text { SUPRATENTORIAL } \\
\text { (PA) }\end{array}$} & \multicolumn{2}{|c|}{$\begin{array}{l}\text { INFRATENTORIAL } \\
\text { (PA) }\end{array}$} & \multirow[b]{2}{*}{$\begin{array}{l}\mathrm{P} \\
\text { Value }\end{array}$} & \multirow[b]{2}{*}{ Corrected } \\
\hline & Mean & $95 \% \mathrm{Cl}$ & Mean & $95 \% \mathrm{Cl}$ & & \\
\hline & 1.52 & \pm 0.26 & 1.68 & \pm 0.1 & 0.16 & 0.24 \\
\hline $\mathrm{K} 2\left(\mathrm{~min}^{-1}\right)$ & 455.6 & \pm 282.1 & 465.2 & \pm 130.2 & 0.94 & 0.94 \\
\hline rCBV & 1.88 & \pm 0.64 & 1.39 & \pm 0.16 & 0.02 & 0.06 \\
\hline
\end{tabular}

Table 3. Comparison of the mean ADC, K2, rCBV for supratentorial versus infratentorial PAs. Significant values are bolded. 


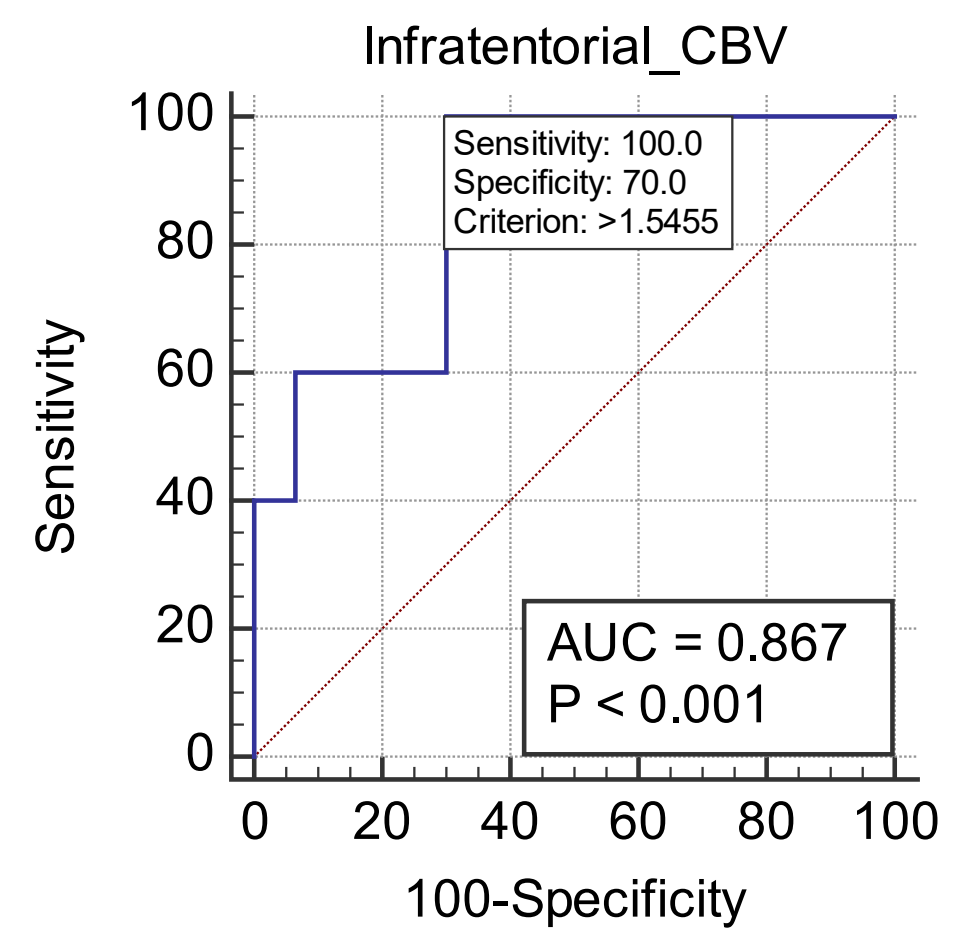

Figure 2. ROC analysis of rCBV values between infratentorial pilocytic and infratentorial pilomyxoid tumors. Threshold criterion corresponding with the highest Youden's index $(\mathrm{J}=0.7)$ is given. 


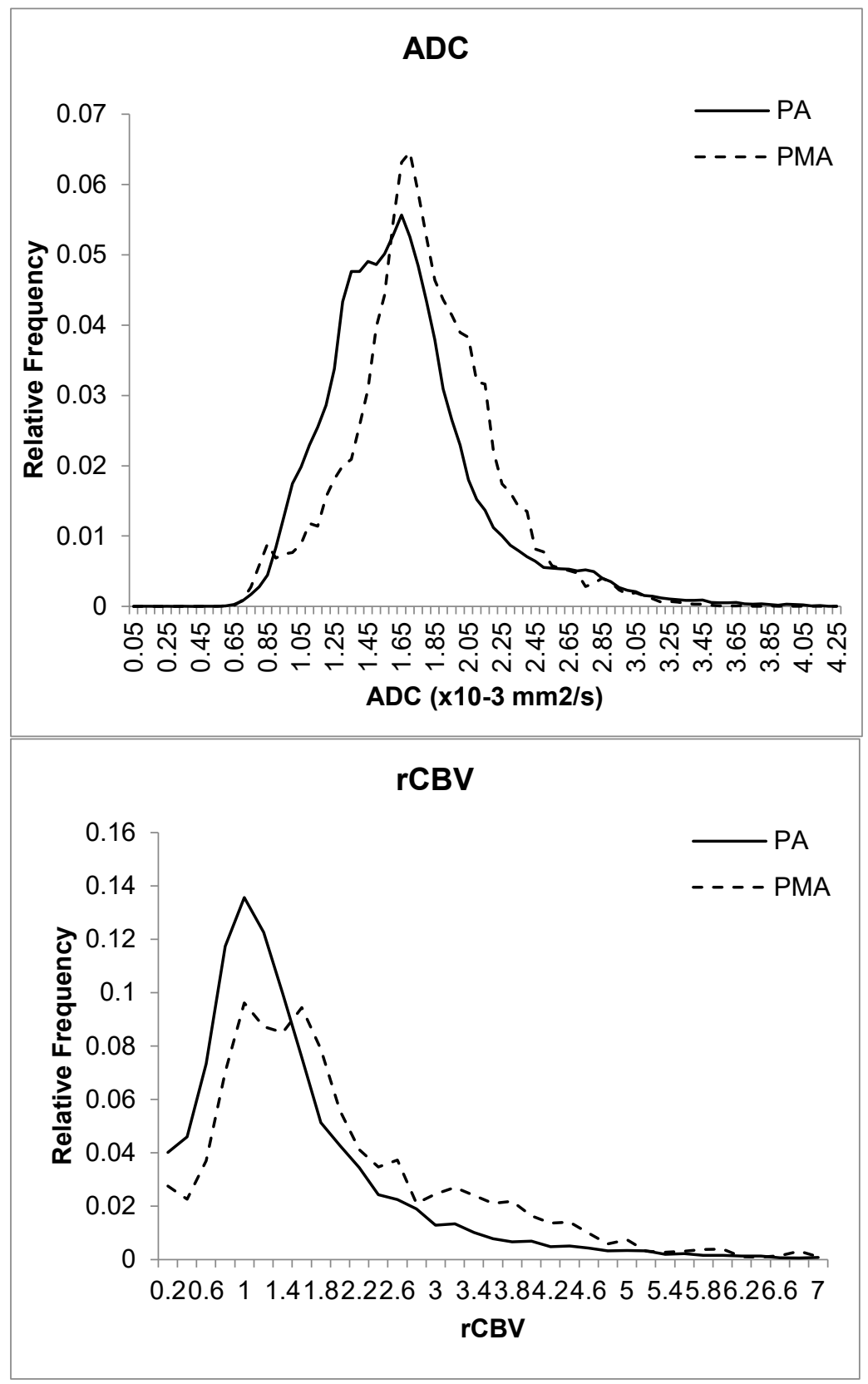

Figure 3. Summation histograms of the relative frequencies of for ADC (a), and $\mathrm{rCBV}(\mathrm{b})$ values for PA and PMA tumors. 


\section{PA}

Average

Standard Deviation

Skew

Kurtosis

Peak Location

Peak Height

(normalized)

5th Percentile

10th Percentile

25th Percentile

50th Percentile

75th Percentile

90th Percentile

95th Percentile

95th - 5th Percentile

50th - 5th Percentile

Avg

1.64

0.36

1.10

3.84

1.56

0.12

1.59

2.08

2.33

1.16
0.06

0.04

0.27

0.81

1.17

0.20

$1.27 \quad 0.21$

0.86

$1.43 \quad 0.23$

0.92

0.27

0.98

1.79

0.36

1.05

0.46

1.24

0.54

1.46

0.49

0.35

$0.42 \quad 0.20$

0.17

0.13

$0.74 \quad 0.38$

1.64

1.71

1.93

2.28

2.68

3.23

3.75

2.28

0.74

0.96

1.57

PMA

$\begin{array}{llllll}\underline{\text { Max }} & \text { Avg } & \underline{\text { Std dev }} & \underline{\text { Min }} & \underline{\text { Max }} & \underline{\text { P Value }} \\ 2.38 & 1.75 & 0.24 & 1.41 & 2.14 & 0.20155 \\ 0.68 & 0.35 & 0.06 & 0.28 & 0.44 & 0.91621 \\ 2.93 & 0.66 & 0.64 & -0.53 & 1.57 & 0.09132 \\ 12.49 & 2.93 & 3.34 & -0.31 & 10.20 & 0.44476 \\ 2.15 & 1.80 & 0.20 & 1.45 & 2.05 & \mathbf{0 . 0 0 4 6 7}\end{array}$

0.09

0.03

0.06

0.16

0.03416

1.20

0.29

0.81

1.85

0.71873

1.32

0.29

0.85

1.90

0.57756

1.55

0.24

1.16

1.97

0.16944

1.75

0.21

1.44

2.07

0.04202

1.93

0.24

1.61

2.25

0.15206

2.16

0.32

1.74

2.65

0.52475

2.35

0.37

1.81

2.84

0.90887

1.15

0.30

0.74

1.69

0.88027

95th - 50th Percentile

0.55

0.15

0.22

0.77

0.02987

0.59

0.26

0.30

1.16

0.14447

Table 4. Analysis of the distribution of ADC values for all PA and PMA tumors. Significant values are bolded. 


\begin{tabular}{|c|c|c|c|c|c|c|c|c|c|}
\hline & $\underline{\text { Infrate }}$ & orial PA & & & Infrat & torial PM & & & \\
\hline & Avg & $\underline{\text { Std dev }}$ & $\underline{\text { Min }}$ & $\underline{\text { Max }}$ & Avg & Std dev & $\underline{\text { Min }}$ & $\underline{\text { Max }}$ & P Value \\
\hline Average & 1.39 & 0.42 & 0.63 & 2.34 & 2.39 & 0.88 & 1.57 & 3.51 & 0.063269 \\
\hline$\underline{\text { Standard Deviation }}$ & 1.05 & 0.46 & 0.22 & 1.90 & 1.36 & 0.58 & 0.62 & 1.96 & 0.313785 \\
\hline Skew & 2.86 & 1.51 & -0.41 & 6.39 & 1.86 & 1.20 & -0.04 & 2.98 & 0.14569 \\
\hline$\underline{\text { Kurtosis }}$ & 15.73 & 14.05 & 0.51 & 63.98 & 8.40 & 7.70 & 1.98 & 21.34 & 0.120723 \\
\hline$\frac{\text { Peak Location }}{\text { Peak Height }}$ & 1.10 & 0.47 & 0.20 & 2.40 & 1.88 & 1.47 & 0.20 & 4.00 & 0.303662 \\
\hline (normalized) & 0.19 & 0.07 & 0.08 & 0.38 & 0.15 & 0.05 & 0.11 & 0.24 & 0.150798 \\
\hline 5th Percentile & 0.37 & 0.23 & 0.01 & 0.80 & 0.97 & 0.70 & 0.06 & 1.86 & 0.12661 \\
\hline 10th Percentile & 0.51 & 0.25 & 0.06 & 0.95 & 1.18 & 0.81 & 0.13 & 2.28 & 0.141865 \\
\hline 25th Percentile & 0.81 & 0.29 & 0.33 & 1.36 & 1.53 & 0.96 & 0.35 & 2.91 & 0.173691 \\
\hline 50th Percentile & 1.16 & 0.37 & 0.61 & 2.15 & 2.09 & 1.01 & 0.95 & 3.58 & 0.108883 \\
\hline 75th Percentile & 1.62 & 0.55 & 0.84 & 3.11 & 2.87 & 0.97 & 1.77 & 4.10 & 0.043196 \\
\hline 90th Percentile & 2.41 & 0.88 & 0.95 & 4.34 & 3.80 & 1.06 & 2.11 & 4.82 & 0.039849 \\
\hline$\underline{\text { 95th Percentile }}$ & 3.24 & 1.25 & 1.02 & 5.58 & 4.80 & 1.49 & 2.47 & 6.31 & 0.077261 \\
\hline 95th - 5th Percentile & 2.86 & 1.28 & 0.64 & 5.18 & 3.83 & 1.56 & 1.68 & 5.72 & 0.245999 \\
\hline 50th - 5th Percentile & 0.79 & 0.36 & 0.24 & 1.95 & 1.12 & 0.38 & 0.73 & 1.72 & 0.130663 \\
\hline 95th - 50th Percentile & 2.07 & 1.06 & 0.30 & 4.15 & 2.71 & 1.61 & 0.95 & 4.82 & 0.432566 \\
\hline
\end{tabular}

Table 5. Analysis of the distribution of rCBV values for infratentorial PA and PMA. Significant values are bolded. 